\title{
É Possível uma Política Criminal? \\ A Discricionariedade no Sistema de Justiça Criminal do DF
}

1. Arthur Trindade M. Costa é pesquisador nível 2 do CNPq e professor de Sociologia da Universidade de Brasília.

\section{Introdução}

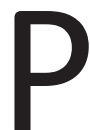

ode-se dizer que ainda são raros os estudos que buscam analisar as políticas públicas de segurança em curso no Brasil. Basicamente, essas políticas refletem a oposição entre prevenção e repressão. Uma das maiores dificuldades encontradas pelos(as) pesquisadores(as) é a precariedade dos critérios e instrumentos empregados na avaliação desse tipo de política pública. De forma geral, tais critérios buscam relacionar policiamento, punição e criminalidade. Fazem isso a despeito dos estudos que têm mostrado o reduzido impacto das estratégias de policiamento nos indicadores de criminalidade (BAYLEY, 1998; BAYLEY \& SKOLNICK, 2002).

Alguns poucos trabalhos buscaram analisar o processo de formulação das 
2. Alguns das resultados da pesquisa podem ser encontrados em Michel Misse (org.), $O$ Inquérito Policial no Brasil: uma pesquisa empírica (Rio de Janeiro: Booklink, 2010). políticas públicas de segurança. Para isso, eles se concentraram em decifrar as ideologias e os conflitos políticos que estão por detrás dessas políticas públicas (SOARES, 2000; BELLI, 2003). A adoção de certas políticas de segurança tem sido determinada muito mais pelo seu apelo eleitoral do que por sua eficácia em lidar com a violência urbana. Há também aquelas pesquisas que procuram analisar as dificuldades de implantar novas políticas no campo da segurança pública (MUNIZ et al, 1997; SINHORETTO et al, 2003; SENTO-SÉ, 2005).

Como em outras áreas, as políticas públicas de segurança têm esbarrado em obstáculos institucionais e na cultura organizacional. Por vezes, são as limitações e os conflitos de competência que dificultam a implantação de novas políticas. Noutras ocasiões, são as estruturas internas das instituições de segurança pública e justiça criminal que dificultam a inovação. Além disso, a cultura organizacional permeada por desconfianças e preconceitos tem dificultado bastante a implantação de novas políticas públicas de segurança.

No que diz respeito especificamente ao Sistema de Justiça Criminal, as pesquisas têm destacado seu caráter desarticulado e estanque (SAPORI, 2007; VARGAS, 2010). Partindo dessa constatação, neste artigo, discutiremos as limitações e os obstáculos para a elaboração e implantação de uma Política Criminal no Distrito Federal. Para isso, analisaremos a forma como o processo de tomada de decisões no interior do Sistema de Justiça Criminal está estruturado. Também avaliaremos como os diferentes atores do sistema interagem.

Para discutir os limites e potencialidades das formas de intervenção do Estado em temas relacionados à segurança pública, é necessário distinguir alguns conceitos. As políticas públicas de segurança (policy) dizem respeito ao conjunto de ações e procedimentos que visam dar conta de determinada demanda ou problema através da alocação de bens e recursos públicos na área de segurança. As estratégias de policiamento (policing) referem-se às diferentes formas de aplicar os efetivos, recursos de poder e equipamentos policiais. Já uma Política Criminal (criminal policy) refere-se à articulação das ações e procedimentos adotados no interior do Sistema de Justiça Criminal com vista a responder a determinado problema ou situação. Na área de segurança pública, as políticas públicas não necessariamente se restringem às estratégias de policiamento e políticas criminais. Envolvem ações de outros atores governamentais e não-governamentais.

Os dados, discursos e observações apresentados neste artigo foram produzidos no curso da pesquisa "O Inquérito Policial no Brasil: uma pesquisa empírica" ${ }^{2}$. A pesquisa etnográfica se deu através de autorização da Direção-Geral da Polícia Civil do Distrito Federal. Após alguns contatos, escolhemos a 6ạ Delegacia de Polícia do Distrito Federal para realizar pesquisa. A escolha se deu pelas seguintes razões: a) tratava-se de uma delegacia circunscricional (de 
atendimento ao público em geral) e não de uma delegacia especializada; b) estar localizada numa região conhecida pelas elevadas estatísticas de violência e criminalidade; c) atender a diferentes tipos de público, dentro de um sincretismo de classes, origens e padrões de cultura e consumo; d) garantia de condições mínimas de acesso favorável aos pesquisadores ${ }^{3}$.

Noutra fase da pesquisa de campo, foram realizados grupos focais com os integrantes das categorias profissionais que têm contato direto com o inquérito policial: agentes, delegados, juízes e promotores. Considerando que, na etapa anterior, foram realizadas etnografias e entrevistas, a técnica do grupo focal foi escolhida no sentido de revelar outras informações a respeito da produção do inquérito policial, como também, com o intuito de aprofundar determinadas questões observadas nas práticas e nos discursos dos atores. Dessa forma, as observações realizadas na 6a DP e as entrevistas exploratórias com os atores do inquérito policial embasaram a seleção dos participantes, a construção dos roteiros e a condução dos grupos focais ${ }^{4}$.

\section{A Governança no Sistema de Justiça Criminal}

As principais políticas públicas na área de segurança e Justiça Criminal são decorrentes de uma complexa e contínua interação entre diversos atores, tanto dentro quanto fora do governo. Essa interação não ocorre em um vácuo organizacional. Ela possui características estruturais muito particulares, que criam limites e possibilidades para a atuação desses atores. A estrutura subjacente a essa interação é denominada "rede de políticas públicas", que pode ser definida como o "conjunto de relações relativamente estáveis entre atores políticos (públicos ou privados) que interagem através de uma estrutura não-hierárquica e interdependente, para alcançar objetivos comuns" (BONAFONT, 2004).

Autonomia e interdependência são as características essenciais das redes de políticas públicas. Os atores políticos, dentro e fora do governo, estabelecem entre si relações não-hierárquicas. Entretanto, estes atores são interdependentes, ou seja, o resultado da ação de cada um depende da participação dos outros. Numa estrutura social dessa natureza, o desafio é estabelecer práticas e espaços sociais não-hierárquicos de coordenação, de forma a obter coerência na ação dos atores que compõem a rede.

Não há dúvida que, para entender as redes de políticas públicas, é fundamental analisar os atores que as compõem, bem como a forma como eles interagem. Entretanto, podemos aprender bem mais sobre as redes se as tomarmos como uma estrutura social que não se limita aos seus atores. Muitas vezes, as propostas e os resultados das políticas públicas não são claramente identificáveis com
3. As etnografias conduzidas sob a minha supervisão foram realizadas por Laíza Mara Neves Spagna e Wélliton Caixeta Maciel.

4. Em 14/05/2009, foi realizado o primeiro grupo focal com 04 juízes. No dia 20/05/2009, foi realizado o segundo grupo com a presença de 05 delegados e, no dia $22 / 05 / 2009$, outro com 05 agentes. Finalmente, no dia $29 / 05 / 2009$, foi realizado grupo focal com 06 promotores. 
os interesses de qualquer dos membros de uma rede. A redes têm dinâmicas próprias que prevalecem sobre as vontades individuais dos seus membros. Portanto, para entendê-las, é necessário analisar os aspectos que condicionam a interação entre os participantes e a capacidade das agências estatais de coordenar as ações dos principais atores políticos. Ou seja, a capacidade de governança do Estado na área de segurança pública.

Enquanto no Brasil a discussão sobre governança ainda é muito incipiente, na Europa e EUA esse debate iniciou-se há cerca de uma década. Talvez em função do pouco tempo, há uma grande confusão sobre o que vem a ser governança e as diversas formas de governança existentes nas sociedades contemporâneas. A literatura existente associa uma enorme variedade de fenômenos, tais como as novas configurações sociais envolvendo múltiplos atores, os novos instrumentos de gestão de políticas públicas e os novos padrões de relacionamento entre o setor público e o setor privado ao conceito de governança. É necessário, portanto, defini-la melhor.

Podemos definir governança como "o direcionamento e a coordenação de atores políticos (normalmente coletivos) a partir de sistemas de normas institucionalizados". A governança das redes de políticas públicas refere-se à capacidade de coordenação das ações dos diversos atores participantes.

Para Peters (1998), coordenação das redes implica na ideia de que as políticas públicas e os programas governamentais são marcados por um grau mínimo de redundância, incoerência e lacuna. A coordenação falha quando duas organizações desempenham as mesmas tarefas (redundância), quando políticas voltadas para o mesmo grupo social possuem diferentes objetivos e requerimentos (incoerência), ou ainda quando existe ausência de políticas e programas voltados para um importante tema ou grupo social (lacuna).

Numa rede de políticas públicas, os problemas de redundância parecem ser de solução mais fácil, uma vez que são mais visíveis. Embora existam argumentos sobre a necessidade de políticas que recubram os mesmos temas e grupos sociais (BENDOR, 1985), num cenário de equilíbrio fiscal, certamente a duplicação de ações não é conveniente.

A existência de lacunas nas políticas públicas é cada vez menos frequente nos estados contemporâneos, dada a enorme diversidade e alcance das ações governamentais. Na maior parte dos casos, a lacuna está relacionada aos problemas de formação da agenda de políticas públicas, aqui definido como o processo pelo qual problemas e alternativas de solução ganham ou perdem atenção do público e dos atores que compõem uma rede de políticas públicas (BIRKLAND, 2005). A literatura mostra que a formação da agenda governamental depende 
das coalizões de defesa que estabelecem em torno de temas e das janelas de oportunidade que possam surgir (KINGDON, 1995). Portanto, os problemas de lacunas referem-se, fundamentalmente, à competição entre atores, internos e externos às redes, para formar a agenda. Não dizem respeito, apenas, às redes de políticas públicas.

Já os problemas de incoerência são típicos das redes com múltiplos atores. Cada ator tem valores, racionalidade e prioridades próprios. Do seu ponto de vista, suas ações são adequadas, enquanto as ações dos outros atores são incoerentes. Conciliar esses diferentes pontos de vista é um dos maiores desafios à coordenação das redes de políticas públicas. A governança dessas redes de políticas públicas implica, fundamentalmente, em reduzir as incoerências de ações entre seus atores.

\section{A Descoberta da Discricionariedade no Brasil}

Nas últimas décadas, temos assistido ao aumento dos estudos sobre o Sistema de Justiça Criminal. Isso foi verificado inicialmente nos EUA, Canadá e Europa. Na América Latina, especialmente no Brasil, os últimos 20 anos foram marcados pela "descoberta" do tema por parte da academia. As pesquisas têm desconstruído antigos modelos normativos sobre o funcionamento das instituições que compõem o sistema e seu relacionamento com a comunidade. Esses estudos têm apontado uma lacuna entre as práticas e a imagem idealizada das Polícias, do Ministério Público e do Judiciário. As principais "descobertas" sobre as práticas cotidianas apontam para a enorme discricionariedade existente Sistema de Justiça Criminal brasileiro.

Sabemos que os acertos informais para lidar com problemas cotidianos são muito mais comuns do que prevê a legislação (MUNIZ, 1999). Os policiais gozam de muito mais discricionariedade nas suas ações do que juízes e promotores estão dispostos a admitir (NASCIMENTO, 2003; SUASSUNA, 2008; SILVA, 2009).

A discricionariedade não se restringe às atividades policiais. Juízes e promotores também gozam de grande liberdade na escolha dos casos que receberão atenção e merecerão trâmite mais rápido. Em grande medida, essas escolhas são condicionadas pela grande demanda de trabalho que o Sistema de Justiça Criminal impõe aos seus operadores. Tanto juízes quanto promotores e policiais se valem de uma variedade de estratégias institucionais para administrar essa demanda de trabalho (cf. MISSE, 2010).

Em função da grande discricionariedade de que gozam os policiais, os estudos mostram que os diretores e comandantes de polícias exercem muito menos 
controle sobre seus subordinados do que estão acostumados a pensar. Ainda são poucas as polícias que dispõem de normas de conduta que orientem a atividade dos seus membros. Mesmo nas polícias que dispõem de normas ou códigos de deontologia, essas não estão incorporadas ao sistema de treinamento e controle (PORTO \& COSTA, 2009).

Com relação ao funcionamento do Sistema de Justiça Criminal, os estudos têm apontado que a opinião pública, a cultura organizacional e as representações sociais têm mais influência sobre as práticas e escolhas feitas pelos profissionais da área do que admite a legislação (PORTO, 2003; SADEK, 2003; AZEVEDO, 2005). As pesquisas têm apontado que tais práticas não estão necessariamente voltadas à defesa da propriedade ou da vida, mas à manutenção de modelos jurídicos voltados para a manutenção da desigualdade nas relações de classe, gênero e raça (PAES, 2010; KANT de LIMA, 2004; ADORNO \& PASINATO, 2007).

Apesar da "descoberta" da discricionariedade no Sistema de Justiça Criminal por parte da academia, magistrados, promotores e governantes ainda têm encontrado dificuldade em admiti-la. De forma geral, a discricionariedade, especialmente aquela relacionada à atividade policial, é percebida como algo negativo, que não deveria existir. Quando explicitados, os casos de discricionariedade são descritos como desvio de conduta, pois o "certo" deveria ser como estabelece a legislação.

Ocorre que a legislação não é clara o suficiente para indicar como e quando proceder. A discricionariedade refere-se à liberdade de escolhas que os profissionais do sistema possuem de facto. Nesse sentido, podemos descrever o Sistema de Justiça Criminal como um conjunto de diversos sistemas de peritos, ou seja, como "sistemas de excelência técnica ou competência profissional que organizam grandes áreas dos ambientes material e social em que vivemos hoje" (GIDDENS, 1991, p. 35). Como em todos os sistemas de peritos, a discricionariedade tem um sinal positivo. Refere-se à liberdade de atuação profissional. Nesse caso, ao invés de negativa, a discricionariedade torna-se parte intrínseca da profissão. O problema deixa de ser a sua existência, mas sim as formas de limitá-la e estruturá-la.

\section{Lidando com a Discricionariedade}

Antes de limitar e estruturar a discricionariedade no Sistema de Justiça Criminal é necessário, portanto, reconhecer a sua existência. Samuel Walker (1995) mostrou que, no caso dos EUA, esse reconhecimento só aconteceu no final da década de 1960. E foi apenas nos meados dos anos 70 que alguns departamentos de polícia daquele país tomaram medidas visando limitá-la e estruturá-la. 
O mesmo pode ser dito com relação ao Canadá e a Inglaterra. Portanto, pode-se dizer que a discricionariedade no SJC, especialmente nas polícias, é uma "descoberta" relativamente recente nesses países.

Segundo Walker, a discricionariedade policial foi "descoberta" no final da década de 60, através de uma pesquisa nacional conduzida pela American Bar Foundation sobre o Sistema de Justiça Criminal. Os resultados da pesquisa evidenciaram o enorme grau de liberdade que os agentes do sistema criminal dispunham quando precisavam tomar suas decisões. Ficou evidente que as ações dos policiais, juízes, promotores e advogados públicos não se limitavam ao texto da lei.

A partir daí, iniciou-se um longo e amplo debate sobre a conveniência e os problemas relacionados ao poder discricionário. Boa parte dos estudiosos do Sistema de Justiça Criminal daquele país passaram a reconhecer os efeitos perversos da discricionariedade. Desde então, a discussão sobre discricionariedade tem girado em torno das áreas onde é possível e necessário limitá-la, bem como sobre as formas mais adequadas de estruturá-la.

Estruturar o poder discricionário no Sistema de Justiça Criminal significa definir as áreas e atividades que precisam de certa liberdade de ação, estabelecer seus limites e preparar os diversos profissionais que atuam no sistema para exercer tal liberdade da forma mais adequada possível aos anseios e necessidade da população (GOLDSTEIN, 2003). A estruturação do poder discricionário não é tarefa fácil, uma vez que não é possível estabelecer orientações sobre todas as atividades e situações com que os policiais se deparam nas ruas. Na prática, somente algumas situações mais sensíveis têm sido objeto de atenção das autoridades policiais, juízes e promotores.

Há inúmeras áreas onde os policiais e demais operadores do Sistema de Justiça Criminal exercem frequentemente sua capacidade discricionária, a saber: a) na aplicação seletiva das leis; b) na escolha dos métodos de intervenção; e c) nas escolhas dos objetivos e prioridades para as políticas de segurança. Para cada área, iniciativas vêm sendo tomadas a fim de limitar e estruturar as escolhas feitas pelos policias.

\section{a) Aplicação Seletiva das Leis}

A polícia é responsável por fazer cumprir todas as leis. Mas, na realidade, o policial frequentemente tem que decidir se irá multar ou não um motorista apressado, registrar ou não uma ocorrência, proibir ou não uma festa barulhenta, para citar apenas algumas poucas situações. Ou seja, o policial pode de facto decidir aplicar a lei ou não.

Essa é uma questão bastante delicada. Juízes e legisladores, via de regra, 
têm sido muito relutantes em aceitar a aplicação seletiva das leis por parte das polícias. Isso implicaria em conferir às polícias poderes muito mais amplos do que hoje vem sendo admitido. Na maior parte dos países, a tendência tem sido negar tais poderes aos policiais, embora na prática eles os possuam. Ao fazerem isso, retiram a possibilidade das polícias estruturarem adequadamente a discricionariedade dos seus membros.

\section{b) Escolhas dos Métodos de Intervenção}

Os policiais precisam decidir sobre como intervir. Podem usar ou não a força que a lei lhes autoriza. Podem também aplicar uma multa ou cassar uma licença de funcionamento. Podem proibir o acesso a uma entrada ou bloquear uma via. Enfim, os policiais dispõem de um número razoável de opções para exercerem a sua autoridade.

Entretanto, a forma como os policiais a usam para intervir nas condutas dos indivíduos e rotinas das comunidades tem grande repercussão sobre a vida das pessoas. Muitas vezes, embora autorizados pela lei, os policiais agem de forma violenta e arbitrária. Isso é particularmente válido para as situações de uso da força letal. Dada a alta repercussão e a gravidade do tema, em dezembro de 1979, a Organização das Nações Unidas (ONU) aprovou a resolução 34/169 que prescrevia a adoção de Códigos de Condutas para todas as polícias do mundo (DAS \& PALMIOTTO, 2002).

Noutras ocasiões, são os policiais que irão de facto selecionar aquelas ocorrências que se converterão em inquérito policial e, a depender a interpretação do Ministério Público, em processo criminal. Os casos de violência doméstica são bons exemplos dessa situação. As polícias têm sido relutantes em tratar os casos de violência doméstica como crime previsto na legislação criminal. A polícia tampouco tem se preocupado em proporcionar um atendimento melhor às vitimas desse tipo de violência.

A partir da década de 80, alguns departamentos de polícia nos Estados Unidos e no Canadá passaram a tentar regular a discricionariedade dos policiais nos casos de violência doméstica. De forma geral, as novas políticas determinam de forma clara e objetiva que, nos casos de violência doméstica, os policiais devem proceder à prisão do(a) agressor(a). Essas políticas ficaram conhecidas como mandatory arrest (prisão obrigatória). No Brasil, a Lei Maria da Penha (11.340/2006) pode ser identificada como uma tentativa de estruturar a discricionariedade policial nos casos de violência doméstica. Apesar dos esforços, ainda são frequentes os casos de descumprimento da lei e das normas de conduta.

\section{c) Escolha de Objetivos e Prioridades}


As polícias são encarregadas de diversas funções, tais como patrulhamento ostensivo, investigação criminal, controle de manifestações, atendimentos a emergências, fiscalização, controle de trânsito, etc. Comandantes e chefes de polícia frequentemente priorizam determinados objetivos em detrimento de outros. Não raro, privilegiam o atendimento a um tipo de problema ou a uma comunidade específica. Tais escolhas são condicionadas por aspectos políticos, sociais e culturais.

O mesmo pode ser dito com relação à atuação dos juízes e promotores. A escoIha dos casos que merecerão maior atenção dos promotores, bem como os que serão processados de forma mais rápida nas varas criminais, não segue apenas o que prescreve a legislação processual penal. As prioridades na tramitação dos processos criminais também são condicionadas por aspectos políticos, sociais e culturais.

De qualquer forma, essa talvez seja a área onde a discricionariedade no Sistema de Justiça Criminal é mais reconhecida. Além disso, é amplamente aceita a ideia de que essas escolhas dizem respeito às políticas de segurança pública e às políticas criminais adotadas em determinado lugar. São escolhas de natureza política e não técnicas e, portanto, devem ser tomadas por um corpo político. Nesse sentido, podemos identificar algumas iniciativas visando ao estabelecimento de órgãos com responsabilidade sobre a elaboração dessas políticas, bem como a ampliação da representatividade e da participação da população no seu processo decisório.

Nos países anglo-saxões (Canadá, EUA, Irlanda e Austrália), alguns departamentos de polícia têm implantado Comitês de Polícia (Police Boards), compostos por membros da sociedade civil, da sociedade política e das instituições que compõem o Sistema de Justiça Criminal. Juntamente com as polícias, o Ministério Público e os governos locais, tais comitês são encarregados de discutir as políticas de segurança pública de forma geral.

Entretanto, tais órgãos têm encontrado dificuldades para se impor junto às polícias e o Ministério Público. Em alguns casos eles não controlam o orçamento dos departamentos de polícia, não possuem autoridade legal sobre os chefes de polícia e promotores, tampouco possuem capacidade técnica para planejar, elaborar e implantar políticas de criminais.

No Brasil, os secretários de segurança pública (e Defesa Social), nomeados pelos governadores eleitos, são os responsáveis, via de regra, pela elaboração das políticas de segurança. Mas, em função da sua limitada competência legal, bem como da precariedade de funcionamento das Secretarias Estaduais de Segurança, os secretários têm encontrado dificuldades para propor diretrizes que 
coordenem a atuação de policiais, promotores e juízes.

Nas últimas décadas, verificamos o surgimento de conselhos comunitários de segurança. Normalmente esses conselhos são resultado da nova filosofia de policiamento comunitário e destinam-se a abrir espaços para os cidadãos participarem da elaboração das políticas de segurança a serem implantadas nas suas comunidades. Nesses casos, atuação dos conselhos tem sido prejudicada tanto pela pouca representatividade dos seus membros, quanto pela baixa participação de membros do judiciário e do Ministério Público.

\section{A Discricionariedade no Sistema de Justiça Criminal no DF}

Observamos que tanto delegados, quanto promotores e juízes estabelecem critérios para selecionar os inquéritos e processos que merecerão atenção. Sem essa seleção de casos, o funcionamento do Sistema de Justiça Criminal seria muito mais caótico do que parece hoje. Ocorre que essa seletividade é feita sem atender a uma Política Criminal ditada pela Direção-Geral da Polícia Civil do Distrito Federal (PCDF), pelo Procurador-Geral do Ministério Público do Distrito Federal e Territórios (MPDFT) ou pelo Presidente do Tribunal de Justiça do Distrito Federal e Territórios (TJDFT).

Além disso, dada a falta de diretrizes institucionais de como proceder a seleção, frequentemente ocorre que os temas priorizados pelos delegados não coincidem com aqueles escolhidos pelos promotores. Os juízes também fazem suas escolhas, mas estas não seguem necessariamente a lógica de seletividade do Ministério Público. Em suma, existem diferentes filtros no Sistema de Justiça Criminal do DF, esses filtros seguem diferentes lógicas e o resultado disso é a ausência de uma Política Criminal coerente.

Apesar de a legislação indicar a necessidade de instauração de inquérito policial sobre todas as notícias-crime, na prática não é bem assim que acontece numa delegacia de polícia. Nem todas as notícias de crime se convertem em Boletim de Ocorrência. E nem todos BOs são transformados em inquéritos policiais (IPs). Fatores ligados à repercussão do crime e ao status social das vítimas contribuem significativamente para a instauração dos IPs. Entretanto, de forma geral, a lógica de seleção dos casos refere-se, muito mais, à necessidade que os delegados e agentes de polícia têm de administrar sua demanda de trabalho.

Certamente, a instauração de um inquérito policial implica na realização de muito trabalho, tanto no que diz respeito à investigação policial, quanto aos procedimentos cartoriais. $\mathrm{O}$ número de inquéritos instaurados numa delegacia de polícia circunscricional, normalmente, é muito grande. Como a tabela 1 abaixo, 
na 6a Delegacia de Polícia foram instaurados mais de 2000 inquéritos sobre roubos, latrocínios e homicídios entre janeiro de 2007 e fevereiro de 2009.

Tabela 1. Homicídios, Latrocínios, Roubos e Inquéritos Instaurados - Paranoá e Itapoá 2007-2008 e 2009

\begin{tabular}{|c|c|c|c|c|c|c|c|c|c|c|c|c|c|c|c|c|c|c|}
\hline & \multicolumn{6}{|c|}{ HOMICÍDIOS } & \multicolumn{6}{|c|}{ LATROCÍNIOS } & \multicolumn{3}{|c|}{ ROUBOS } & \multicolumn{3}{|c|}{ IP's } \\
\hline & \multicolumn{2}{|c|}{ 空 } & \multicolumn{2}{|c|}{ 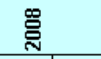 } & \multicolumn{2}{|c|}{ 을 } & \multicolumn{2}{|c|}{ స్ } & \multicolumn{2}{|c|}{ 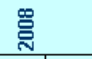 } & \multicolumn{2}{|c|}{ 号 } & \multirow[t]{2}{*}{ 空 } & \multirow[t]{2}{*}{ 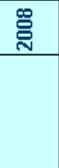 } & \multirow[t]{2}{*}{ 号 } & \multirow[t]{2}{*}{ 空 } & \multirow[t]{2}{*}{ 号 } & \multirow[t]{2}{*}{ 을 } \\
\hline & 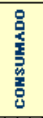 & 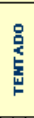 & 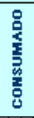 & 总 & 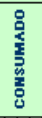 & 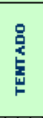 & 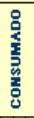 & 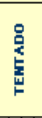 & 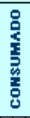 & 总 & 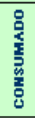 & 总 & & & & & & \\
\hline UANE $R O$ & 5 & 4 & 4 & 4 & 5 & 8 & 0 & 1 & 0 & 1 & $\mathbf{0}$ & 1 & 83 & 83 & 0 & 56 & 80 & 91 \\
\hline FEVEREIRO & 7 & 8 & 3 & 1 & 6 & 9 & 1 & 1 & 0 & 1 & $\mathbf{0}$ & 1 & 94 & 85 & 105 & 70 & 102 & 94 \\
\hline BARCOO & 2 & 9 & 2 & 4 &  & 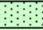 & 0 & 2 & 0 & 4 & & & 112 & 83 & & 72 & 93 & \\
\hline ABRIL & 8 & 7 & 5 & 4 & & & 0 & 0 & 0 & 0 & & & 65 & 100 & & 89 & 81 & \\
\hline BARO & 5 & 6 & 1 & 1 & 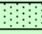 & 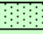 & 0 & 2 & 3 & 1 & & & 71 & 81 & & 113 & 49 & \\
\hline JUNHO & 2 & 8 & 3 & 3 & & & 1 & 0 & 1 & 0 & & & 66 & 128 & & 79 & 61 & \\
\hline WULQ & 2 & 5 & 5 & 3 & 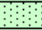 & ) & 0 & 1 & 1 & 1 & & & 75 & 107 & & 66 & 92 & \\
\hline AGOSTO & 1 & 5 & 1 & 3 & & & 0 & 1 & 0 & 0 & & & 79 & 126 & & 68 & 76 & \\
\hline SETEB & 6 & 2 & 6 & 3 & 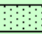 & 1 & 0 & 1 & 0 & 2 & & & 95 & 119 & & 58 & 76 & \\
\hline OUTUBRO & 1 & 7 & 5 & 6 & & & 0 & 1 & 0 & 1 & & & 91 & 114 & & 73 & 136 & \\
\hline ADOF & 5 & 5 & 3 & 8 & & $\therefore$ & 0 & 1 & 0 & 1 & & & 67 & 108 & & 60 & 87 & \\
\hline DEZEMBRO & 2 & 8 & 4 & 7 & & & 0 & 3 & 0 & 1 & & & 83 & 109 & & 62 & 67 & \\
\hline TOTAL & 46 & 74 & 42 & 47 & 11 & 17 & 2 & 14 & 5 & 13 & 0 & 2 & 981 & 1243 & 195 & 866 & 1000 & 185 \\
\hline
\end{tabular}

Fonte 6a Delegacia de Polícia - PCDF

Por orientação do delegado-chefe, apenas nos casos de flagrante ou homicídios dolosos os inquéritos são obrigatoriamente instaurados. Nos demais casos, cabe ao delegado-chefe verificar se no Boletim de Ocorrência já existem elementos de prova necessários para a conclusão de um inquérito. Ou seja, se existem informações sobre a autoria do crime (i.e., filmagens, depoimentos, testemunhas).

O Paranoá tem 1500, 1600 roubos por ano mais ou menos, transeunte, tal e tal. E não dá pra relatar todos, não dá pra instaurar inquérito pra todos, não dá pra relatar todos. Então o que acontece é que a gente mira naqueles que tem possibilidade de êxito, porque sabe que prendendo o autor de um dos roubos, você vai identificar o autor de pelo menos 10, porque ele não fez só aquele. (Delegado)

Aí a gente instaura o inquérito quando tem elementos para instruir, se não a gente teria um inquérito que seria com trinta dias, acabaria com capa, portaria, ocorrência, laudo de avaliação econômica e declarações da vítima. (Delegado)

Geralmente, nos Boletins de Ocorrência, onde esses elementos não estão presentes, os inquéritos não são instaurados. Somente em casos excepcionais procede-se a investigação preliminar para levantar novas informações. Esses casos excepcionais referem-se à natureza da vítima ou à repercussão do crime. Em resumo, é a necessidade de administrar o trabalho que rege a seleção dos casos a serem instaurados inquéritos. Existindo elementos jurídicos suficientes, 
instaura-se inquérito, senão, arquiva-se a ocorrência.

A necessidade de administrar a demanda de trabalho, também está presente no cotidiano de promotores e juízes. Para os delegados, controlar a instauração dos inquéritos é ferramenta importante nesse esforço. Já para os promotores, é através do controle das denúncias oferecidas que o volume de trabalho é administrado. Entretanto, a qualidade das provas não é o único elemento a ser considerado na apresentação de uma denúncia. O tipo de crime, a repercussão do caso, o status da vítima também serão considerados. O principal recurso para isso não é o pedido de arquivamento, mas sim o pedido de novas diligências.

$\mathrm{O}$ que a gente percebe na prática, principalmente em delitos de pena menor, é que muitas vezes o promotor faz o pedido de novas exigências simplesmente porque ele não está disposto a oferecer a denúncia. (Delegado)

O excessivo volume de inquéritos policiais instaurados não permite que todos sejam analisados "capa a capa" e alguns acabam sendo arquivados ou "mandados pela baixa". Para isso, os promotores definem critérios, normalmente definidos pela demanda e pelo contexto. Se em uma área um determinado tipo de crime, por alguma razão, exige uma atenção maior, ele é eleito como prioritário. A formação e especialização do promotor também pesam nesse quesito. (Promotor)

Nas varas criminais, a situação não é muito diferente. O volume de trabalho precisa ser administrado. Aqui, no entanto, o trabalho a ser administrado é a realização de audiências e o seu principal instrumento de gestão é o controle da agenda. Para selecionar os casos prioritários, além dos critérios previstos em lei (i.e., réu preso), consideram-se os aspectos relativos ao tipo de crime, a repercussão do caso e status da vítima.

(...) tem um problema seríssimo que tá acontecendo, que é o acúmulo de serviço. Não só do delegado, do promotor, do juiz. Não há tempo (...). (Juiz)

Começar a ser seletivo com os processos de réu solto. Correm os processos de réu preso, e os processos de réu solto você começa a ser seletivo. A primeira seletividade vem do Ministério Público quando pede arquivamento, e você mau olha e arquiva tudo. Segundo, é começar a intransigir com algumas teses jurídicas, por exemplo o princípio da insignificância, o princípio da bagatela, e você começa a arquivar, ou dar benefícios que a rigor você nem gostaria de dar mais. É melhor uma resposta penal mínima do que nenhuma resposta penal. Aí se a vara bagunça demais, como a vara dela estava, como estava no Paranoá, antes de ir pra São Sebastião, você escolhe o tipo de crime e atua neles, o resto fica no armário esperando prescrever. (Juiz) 
A existência da seletividade no Sistema de Justiça Criminal diz respeito à discricionariedade que delegados, promotores e juízes possuem. Sem essa discricionariedade, não seria possível administrar o trabalho de uma delegacia de polícia, de uma promotoria de justiça ou de uma vara criminal. A seletividade dos casos está relacionada, portanto, às atribuições desses profissionais do Sistema de Justiça Criminal.

O estabelecimento de uma Política Criminal diz respeito à coordenação das diferentes seletividades existentes num Sistema de Justiça Criminal. Entretanto, para que isso ocorra, é necessário um espaço (i.e., fórum, conselho, comitê) de diálogo e discussão entre os diferentes operadores do sistema. Noutras palavras, é necessário articular uma rede de delegados, promotores e juízes. Uma Política Criminal implica que os profissionais priorizem o mesmo tipo de crime ou situação, diminuam a redundância de trabalho e evitem lacunas com relação aos tipos de provas necessários para uma condenação judicial.

De forma geral, a escolha dos crimes a serem priorizados é feita de forma bastante incoerente, uma vez que juízes, promotores e delegados utilizam critérios distintos de seletividade. Além disso, o Sistema de Justiça Criminal apresenta também algumas redundâncias, que se transformam em perda de tempo. É o caso de alguns relatórios elaborados pelos delegados e inseridos no final dos inquéritos policiais. Para boa parte dos promotores, o relatório do delegado é excessivamente longo, contendo interpretações jurídicas pouco úteis para a elaboração da denúncia. Ao contrário do relatório de investigação, que apresenta as provas coletadas e uma conclusão sucinta. No Distrito Federal, não há orientações claras sobre a estrutura e conteúdos necessários num inquérito policial.

Relatório de inquérito pra gente é algo praticamente inútil. $O$ que a gente precisa, como promotor de justiça, no inquérito, não é de uma síntese daquilo que aconteceu. A gente precisa de informação. O relatório de juízo de valor de prova testemunhal, esse não interessa. O que interessa é o relatório técnico. (Promotor)

Há, também, lacunas com relação aos elementos de prova. Em alguns inquéritos relatados, as provas apresentadas não são suficientes e, tampouco, necessárias para uma condenação. Isso ocorre porque a legislação brasileira não faz distinção entre prova, evidência e indício. Tampouco há normas ou diretrizes na PCDF sobre os tipos de provas que devem ser priorizados na investigação de cada crime, a despeito de ser quase que consensual entre os juízes que um inquérito bem feito é aquele que contém prova pericial. Para os magistrados, em alguns casos, as provas testemunhais (especialmente os testemunhos de policiais) têm menor valor condenatório. 
É consenso que o contato pessoal entre a Polícia e o Ministério Público é algo muito excepcional.

[O contato entre delegados e promotores] em $99 \%$ dos casos é no papel (...) é possível ligar? É. De vez em quando a gente faz? Faz. Mas eu diria assim, que o rotineiro, o dia-a-dia é através de ofício. Então aquilo que a gente tem que falar a gente coloca no papel, escreve, assina e manda. (Promotor)

O baixo grau de interação e a excessiva formalidade nas relações entre delegados e promotores é resultado da falta de reconhecimento da discricionariedade na atividade policial. Uma vez que ela não existe, ou não deveria existir, não faz sentido tentar articular as escolhas feitas por delegados e promotores. Nesse caso, ganha destaque o papel de "fiscal da lei" desempenhado pelo Ministério Público. Uma vez que cabe também ao Ministério Público zelar pela legalidade dos procedimentos de investigação, seria importante marcar ao máximo a distância entre promotores e delegados.

Tem gente que critica [a proximidade entre delegados e promotores], acha que não pode haver uma fixação de políticas de ação institucional, um plano de estratégias de ação, de solução de alguns crimes (...) Isso acabaria atingindo o caráter de fiscal da lei do promotor. (Delegado)

Embora possamos dizer que, de forma geral, a articulação entre delegados, promotores é pouco frequente, há algumas exceções importantes. Quando existem delegacias e promotorias especializadas, a situação muda radicalmente. Nesses casos, a articulação das ações de delegados e promotores parece ser muito maior.

Sobre essa questão de relacionamento com promotor, eu tenho duas experiências especializadas. Na DEMA [Delegacia do Meio Ambiente] em 2002, então eram 8 promotores da PROURBI [Promotoria da Ordem Urbana] e da PRODEMA [Promotoria de Defesa do Meio Ambiente] e hoje tenho experiência com mais 8 promotores, das promotorias especializadas em repressão às drogas. Então, nas duas experiências, eu percebi o seguinte: você tem necessariamente um contato muito maior. Porque você acaba lidando com a maior parte do trabalho daqueles promotores. (Delegado)

Eu acho que as autoridades da persecução criminal, os delegados e o Ministério Público, podem montar uma política: 'olha, nos vamos reprimir esse crime agora, não é que eu vou deixar o outro, mas os nossos esforços, em termos de ministério público, e em termos de polícia seria 
determinado para a repressão ao sequestro relâmpago'. Ou 'Brasília está com um número muito alto de roubo, nós vamos focar nos roubos'. Nos vamos usar nossos serviços materiais e de pessoal, e centralizar isso. (Delegado)

Nas delegacias especializadas, geralmente, primeiro procede-se a investigação criminal, realizam-se escutas telefônicas e campanas. Uma vez feito o levantamento de informações, deflagra-se uma operação policial, cujo objetivo é a prisão em flagrante dos suspeitos. Só depois do flagrante que o inquérito é instaurado. Normalmente há uma articulação entre delegados e promotores sobre os procedimentos de investigação. Da mesma forma que, não raro, acorda-se sobre as prioridades da investigação. Apesar da redução de lacunas, redundâncias e incoerências, esse tipo de articulação não tem como origem a direção da Polícia Civil ou do Ministério Público.

\section{Conclusão}

No Distrito Federal, as interações entre Delegados, promotores e juízes são pouco frequentes e marcadas pelo formalismo. Essa constatação confirma a tese de que o Sistema de Justiça Criminal Brasileiro é pouco articulado. Neste artigo, buscamos analisar o que está por trás dessa desarticulação.

Em parte, essa desarticulação assenta-se no não reconhecimento da discricionariedade que, de fato, gozam os operadores do sistema, especialmente os policiais. Dessa forma, as escolhas que delegados, promotores e juízes fazem cotidianamente são orientadas por critérios diferentes. Pior ainda, priorizam crimes e situações distintas.

Embora não existam, no Distrito Federal, iniciativas para articular as ações no interior do Sistema de Justiça Criminal, a análise das delegacias e promotorias especializadas nos permite pensar que, sim, é possível uma Política Criminal. Para isso, entretanto, é necessário melhorar a comunicação entre os atores do sistema, bem como reconhecer que todos fazem escolhas que são inerentes ao exercício das suas profissões.

Abstract: In this article we discuss the limits and obstacles to the creation and implementation of a criminal policy in the Brazilian Federal District. So, we analyze how the decision making process in the Criminal Justice System has been structured. We observed, through ethnographies and focus groups, that commissioners, attorneys and judges have been established their own criteria to select police inquiries and criminal procedures. There are different biases in the 
Criminal Justice System of Federal District that follow different logics, whose consequence is the lack of a coherent criminal policy. The causes of this are the no recognition of the discretion in the Criminal Justice System and, consequently, it no structuration.

Keywords: Police inquiry, Discretion, Criminal Justice System, Federal District, Brazil.

\section{Referências Bibliográficas}

Adorno, Sérgio \& Pasinato, Wânia (2007) "A justiça no Tempo, o Tempo da Justiça. Tempo Social”. Revista de Sociologia da USP. v. 19: 131-155.

Azevedo, Rodrigo G. (2005) "Perfil Socioprofissional e Concepções de Política Criminal do MP/RS", trabalho apresentado no XII Congresso Brasileiro de Sociologia, Belo Horizonte.

Bayley, David (ed.) (1998) What Works in Policing. New York: Oxford University Press.

Belli, Benoni (2003) Violência, Tolerância Zero e Democracia no Brasil: paradoxos da década de 90. Tese de Doutorado, UnB.

Bendor, J.B. (1985) Parallel Systems: redundancy in government. Berkeley: University of Berkeley Press.

Birkland, Thomas A. (2005) An Introduction to The Policy Process: Theories, Concepts, And Models of Public Policy Making. New York: M. E. Sharpe.

Bonafont, Laura Chaqués (2004) Redes de Políticas Públicas. Madrid: Siglo Vientiuno de Espana Editores.

Das, Dilip \& Palmiotto, Michael (2002) “International Human Rights Standards: Guidelines for the World's Police Officers". Police Quarterly, vol. 5, n. 2.

Giddens, Anthony (1991) As Conseqüências da Modernidade. São Paulo: Ed. Unesp.

Goldstein, Herman. (2003) Policiando uma Sociedade Livre. São Paulo: Ed. USP.

Kant de Lima, Roberto (2004) "Direitos Civis e Direitos Humanos: uma tradição judiciária pré-republicana?". São Paulo em Perspectiva, vol. 18: 49-59.

Kingdom, John W. (1995) Agendas, Alternatives, and Public Policies. New York: Harper Collins College Publishers. 
Misse, Michel (org.) (2010) O Inquérito Policial no Brasil: uma pesquisa empírica Rio de Janeiro: Booklink.

Muniz, Jacqueline et al (1997) "Resistência e Dificuldades de um Programa de Policiamento Comunitário”. Tempo Social, vol. 9, n. 1.

Muniz, Jacqueline. (1999) Ser Policial É Sobretudo Uma Razão de SER: Cultura e Cotidiano da Polícia Militar do Estado do Rio de Janeiro. IUPERJ, Tese de Doutorado.

Nascimento, Nívio C. (2003) Entre as Leis e o Mundo: polícia a administração de conflitos numa perspectiva comparativa. Universidade de Brasília, Tese de Doutorado.

Paes, Vivian F. (2010) Como se Contam Crimes: um estudo sobre a construção social do crime no Brasil e na França. Universidade Federal do Rio de Janeiro, Tese de Doutorado.

Peters, Guy B. (1998) "Managing the Horizontal Government." Public Administration: 295-311.

Porto, Maria Stela G. \& Costa, Arthur T. M. (2009) “Códigos de Deontologia Policial no Brasil e no Canadá: análise dos documentos e representações sociais". Coleção Segurança com Cidadania, vol. 1: 57-82.

Porto, Maria Stela Grossi (2004) "Polícia e Violência: representações sociais de elites policiais no Distrito Federal". São Paulo em Perspectiva. S. Paulo, v. 18, n. 1: 132-141, 2004.

Sadek, Maria Tereza (2003) "Delegados de Polícia: quem são e o que pensam". Rio de Janeiro: Cadernos Adenauer.

Sapori, Luis Flavio. (2007) Segurança Pública no Brasil: desafios e perspectivas. Rio de Janeiro: Editora FGV.

Silva, Gilvan G. (2009) A Lógica da Polícia Militar do Distrito Federal na Construção do Suspeito. Universidade de Brasília, Dissertação de Mestrado.

Skolnick, Jerome \& Bayley, David (2002) Policiamento Comunitário: Questões e Práticas Através do Mundo. São Paulo: EDUSP.

Soares, Luiz Eduardo (2000) Meu Casaco de General: 500 dias no front da segurança pública do Rio de Janeiro. São Paulo: Cia das Letras. 
Vargas, Joana (2010) "Uma Abordagem Empírica do Inquérito Policial: o caso de Belo Horizonte", in Michel Misse (org.), O Inquérito Policial no Brasil: uma pesquisa empírica. Rio de Janeiro: Booklink.

Walker, Samuel (1993) Taming the System: The Control of Discretion in Criminal Justice, 1950-1990. New York: Oxford University Press. 